\title{
On 3D Topological Relationships
}

\author{
Siyka Zlatanova \\ Section GIS technology, Department of Geodesy, TUDelft \\ Thijsseweg 11,2629 JA Delft, The Netherlands \\ s.zlatanova@geo.tudelft.nl
}

\begin{abstract}
This paper presents an integrated study on possible topological relationship between multidimensional simple objects in 0,1,2 and $3 \mathrm{D}$ space. The formal categorisation of spatial relationships is completed upon the 9intersections model. The focus is on the definition of a unified set of conditions for eliminating relationships that cannot be realised in reality. The negative conditions are formulated on the basis of dimension and co-dimension of objects, and connectivity of boundaries. The set of 25 conditions is sufficient for deriving all the possible relationships mentioned currently in the literature and for specifying the relationships between surface and surface in $3 D$ space. Drawings of example configurations verify the obtained results in $3 D$ space.
\end{abstract}

\section{Introduction}

The topological spatial relationships gain an increasing attention in the last decade. The topic of research has shifted from issues related to the definition of a particular formalism to represent topological relationships, to implementation issues (see [2], [3], [12]). An important implementation aspect (in terms of performance) is the specification of the spatial relationships (within a given framework) that exist in reality. While a lot of research is already carried out in the clarification of the relationships between spatial objects (points, lines and regions) in 2D space, the investigations in 3D space are fragmented and incomplete. This work is a contribution to the clarification of the relationships between simple spatial objects in 3D space and the total number of relationships that can occur in reality.

To identify the spatial relationships between two objects in 3D space, we use the 9-intersection model (see [7]), which was approved by the OpenGIS consortium as a basic framework for implementation. Suppose two simple spatial objects $A$ and $B$ are defined in the same topological space $\Lambda$ and their boundary, interior and exterior are denoted by $\partial A, A^{\circ}, A^{-}, \partial B, B^{\circ}$ and $B^{-}$. The binary relationship $R(A, B)$ between the two objects is then identified by composing all the possible set intersections of the six topological primitives, i.e. $A^{\circ} \cap B^{\circ}, \partial A \cap B^{\circ}$, $A^{-} \cap B^{\circ}, \quad A^{\circ} \cap \partial B, \quad \partial A \cap \partial B, \quad A^{-} \cap \partial B, \quad A^{\circ} \cap B^{-}$ $\partial A \cap B^{-}$and $A^{-} \cap B^{-}$, and detecting empty ( $\varnothing$ ) or non-empty $(\neg \varnothing)$ intersections. For example, if two objects have a common boundary, the intersection between the boundaries is non-empty, i.e. $\partial A \cap \partial B=\neg \varnothing$; if they have intersecting interiors, then the intersection $A^{\circ} \cap B^{\circ}$ is not empty, i.e. $A^{\circ} \cap B^{\circ}=\neg \varnothing$. Since in principle each pair of intersections can have either the empty or non-empty value, different "patterns" define different relationships. Although, the theoretical number of all the relationships that can be derived from the 9 intersections is $2^{9}$, i.e. 512 relationships, only a small number of them can be seen in reality. The way to specify possible relationships is based on the elimination of impossible ones. To eliminate non-realisable relations, conditions, referred to as negative conditions, are composed. Some intersections (or a combination of intersections) between topological primitives can never occur in reality, and all the relationships that contain these intersections (or the combination) can be securely excluded from further considerations.

On the basis of the 9 intersections between topological primitives and following the "elimination-of-impossiblerelationships" approach, several authors have identified relationships between spatial objects. Egenhofer and Herring [6], Kufoniyi [10] investigate relationships between spatial objects in 2D space. Egenhofer [5] presents relationships among $3 \mathrm{D}$ objects in $3 \mathrm{D}$ space. Bric [1] investigates the largest combinations of objects, using the basic set of conditions introduced by van der Meij [11]. De Hoop et al [4] report a slightly modified approach to derive relationships between multidimensional objects in 3D space. The studies related to the 3D space are not convincing. Basically, the authors agree on the number of most of the relationships with one exception, i.e. surface and surface in 3D space. However, sketches of possible configurations in 3D space are not provided and the reader intuitively attempts to check results and conditions. The negative conditions used by the authors, however, vary significantly and complicates their comparison. For example, Egenhofer and Herring [6] present 23 negative conditions for relationships in $2 \mathrm{D}$ space. To cover the 3D situations, 15 more conditions are added by van der Meij [11]. Bric [1] operates with 40 conditions. Most of the conditions are related to a particular configuration of objects (e.g. conditions for line 
and line), which leads to further duplications of the effect of some of them.

This paper aims at providing a systematised and integrated method for deriving relationships between multidimensional spatial objects. For the purpose, first a unified set of negative conditions is defined and second the possible relationships between objects of any dimension in $0,1,2$ and 3D space are derived.

\section{Negative conditions}

The types of objects considered here correspond to simple geometric objects as they are defined in OpenGIS (http://www.opengis.org) specifications. The 0, 1,2 and 3D objects are referred to as points, lines, surfaces and bodies with corresponding notations $\mathrm{P}, \mathrm{L}, \mathrm{S}$ and $\mathrm{B}$. Thus the notation $\mathrm{R}(\mathrm{L}, \mathrm{S})$ means that the binary relationship concerns line and surface as the line is the first object. The relationship $\mathrm{R}(\mathrm{S}, \mathrm{L})$ is the converse relationship, which is referred to by the vice versa part of the condition.

For simplicity, all the intersections will be represented in a vector form and the empty and non-empty set will be denoted by 0 and 1 . Thus, each relationship (being a sequence of 0 and 1) corresponds to a binary number, which can be transformed to a decimal number (see [9], [10]). For example, the relationship between objects with non-intersecting boundaries and interiors can be represented as 000011111 , which is the decimal number 31. This number will be denoted as a decimal code R031 (the 'disjunct' relationship). It is apparent that different ordering of the intersections will result in a different decimal code. In this text, we will use the order shown in Table 1 .

The value of intersections (empty, non-empty) between interior, boundary and exterior depends on three parameters: the dimension of the objects, the dimension of the space (related to the co-dimension of the object) and the type of boundary (connected or disconnected) (see [5] [8]). The three parameters, however, cannot be used to define straightforward negative conditions because each configuration of objects has different parameters. Still many of the negative conditions are derived on the basis of one or another parameter that is used here to introduce grouping of conditions. To avoid multiple expression of the same conditions, the negative conditions that can be found among the ones given by Egenhofer and Herring 1992 are represented by the same verbal expression. These conditions, denoted by $E H$ (in brackets) are explicitly mentioned. All the negative conditions are shown in Table 1. The following text presents the negative conditions $\mathrm{C}$ (in italic) distributed in 12 groups (in bold) for objects with non-empty boundary. The conditions for relationships specific for objects with empty boundaries are given in the group 13 .
1. Any objects: $R(L, L)$ in IR; R(L,L), R(S,S), R(L,S) and $R(S, L)$ in $I^{2} ; R(L, L), R(S, S), R(B, B), R(L, S)$, $\mathbf{R}(\mathrm{L}, \mathrm{B}), \mathbf{R}(\mathrm{S}, \mathrm{B}), \mathbf{R}(\mathrm{S}, \mathrm{L}), \mathbf{R}(\mathbf{B}, \mathrm{L}), \mathbf{R}(\mathbf{B}, \mathbf{S})$ in $\mathbf{I R}^{3}$.

$C 1$. The exteriors of two objects always intersect (EHI). $C 2$. If A's boundary intersects with B's exterior then A's interior intersects with $B$ 's exterior too and vice versa (EH3).

C3. A's boundary intersects with at least one part of B and vice versa (EH5).

After the first three negative conditions, the number of possible binary relationships is reduced to 104 for spatial objects with equal dimensions and to 160 for spatial objects with different dimensions.

2. Objects with equal dimensions: $R(L, L)$ in $\mathbb{I R}_{\text {; }}$ $R(S, S)$ and $R(L, L)$ in $\mathbb{R}^{2} ; R(L, L), R(S, S)$ and $R(B, B)$ in $\mathbf{I R}^{3}$.

C4. If both interiors are disjoint then A's interior intersects with $B$ 's exterior and vice versa (EH2).

C5. If A's interior intersects with B's boundary, then it must also intersect with $B$ 's exterior and vice versa (EH4).

$\mathrm{C} 5 \mathrm{a}$ can be applied also for relationships when the first object $\mathrm{A}$ has the higher dimension. However, this is not necessary because the condition C6 (also valid for such objects) eliminates these combinations (compare $\mathrm{C} 5_{\mathrm{a}}$ and C6 in Table 1), i.e. C6 is more restrictive than $\mathrm{C}_{\mathrm{a}}$.

3. Objects with different dimensions: $R(S, L)$, $R(L, S)$ in $\mathbb{R}^{2} ; R(B, L), R(L, B), R(B, S)$, and $R(S, B)$ in $\mathbf{I R}^{3}$.

C6. The closure of higher-dimensional object A always intersects with the exterior of $B$ (old: $E H$ 16,17; new: $\left.C 6_{c}, C 6_{d}\right)$.

If the two objects have different dimensions, their boundaries never coincide, i.e. $\partial A \neq \partial B$. This implies that both the boundary and the interior of the object of the higher dimension intersect with the exterior of the object of the lower dimension.

4. Objects with different dimensions and one of the objects with zero co-dimension: $R(L, S)$ and $R(S, L)$ in $I^{2} ; \mathbf{R}(\mathbf{L}, \mathbf{B}), \mathbf{R}(\mathbf{S}, \mathbf{B}), \mathbf{R}(\mathbf{B}, \mathbf{L})$ and $\mathbf{R}(\mathbf{B}, \mathbf{S})$ in $\mathbf{I R}^{3}$.

C7. The interior of A always intersects with at least one of the three topological primitives of $B$ and vice versa (new).

If both interiors are disjoint, then the interior of the object with the lowest dimension (e.g. A) can be a subset of either the boundary or the exterior, or both, of the opposite object (e.g. B). This means if the interior of $\mathrm{A}$ does not intersect with the boundary of $\mathrm{B}$, it must intersect with its exterior. The condition is true for all the relationships between objects of the same dimension, i.e. $\mathrm{R}(\mathrm{L}, \mathrm{L}), \mathrm{R}(\mathrm{S}, \mathrm{S})$ and $\mathrm{R}(\mathrm{B}, \mathrm{B})$, as well. However, the more restrictive condition $C 4$, is applied in these cases.

5. At least one of the objects has zero co-dimension: $R(L, L)$ in $\mathbb{R} ; R(S, S), R(L, S)$ and $R(S, L)$ in $\mathbb{R}^{2} ; R(L, B)$ $\mathbf{R}(\mathrm{S}, \mathrm{B}), \mathbf{R}(\mathbf{B}, \mathrm{L}), \mathbf{R}(\mathbf{B}, \mathbf{S}), \mathbf{R}(\mathbf{B}, \mathbf{B})$ in $\mathbb{R}^{3}$. 
Table 1: Negative conditions for eliminating impossible relationships in $0,1,2$ and 3D space (see text for specification of operands A and B)

\begin{tabular}{|c|c|c|c|c|c|c|c|c|c|}
\hline 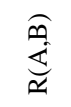 & 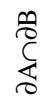 & $\begin{array}{l}00 \\
\stackrel{0}{C} \\
0 \\
\text { \& }\end{array}$ & $\begin{array}{l}\stackrel{0}{n} \\
\frac{1}{0}\end{array}$ & $\begin{array}{l}\mathscr{f} \\
\text { ठ } \\
\&\end{array}$ & $\begin{array}{l}1 \\
c \\
1\end{array}$ & 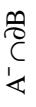 & $\begin{array}{l}\stackrel{0}{m} \\
\text { cै } \\
\ll\end{array}$ & 离 & 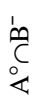 \\
\hline $\mathrm{C} 1$ & - & - & - & - & 0 & - & - & - & - \\
\hline $\mathrm{C} 2_{\mathrm{a}}$ & - & - & - & - & - & - & - & 1 & 0 \\
\hline $\mathrm{C} 2_{\mathrm{b}}$ & - & - & - & - & - & 1 & 0 & - & - \\
\hline $\mathrm{C} 3_{\mathrm{a}}$ & 0 & - & 0 & - & - & - & - & 0 & - \\
\hline $\mathrm{C} 3_{\mathrm{b}}$ & 0 & - & - & 0 & - & 0 & - & - & - \\
\hline $\mathrm{C} 4_{\mathrm{a}}$ & - & 0 & - & - & - & - & - & - & 0 \\
\hline $\mathrm{C} 4_{\mathrm{b}}$ & - & 0 & - & - & - & - & 0 & - & - \\
\hline $\mathrm{C} 5 \mathrm{a}$ & - & - & - & 1 & - & - & - & - & 0 \\
\hline $\mathrm{C} 5_{\mathrm{b}}$ & - & - & 1 & - & - & - & 0 & - & - \\
\hline $\mathrm{C6}_{\mathrm{a}}$ & - & - & - & - & - & - & - & - & 0 \\
\hline $\mathrm{C} 6_{\mathrm{b}}$ & - & - & - & - & - & - & - & 0 & - \\
\hline $\mathrm{C} 6_{\mathrm{c}}$ & - & - & - & - & - & 0 & - & - & - \\
\hline $\mathrm{C} 6_{\mathrm{d}}$ & - & - & - & - & - & - & 0 & - & - \\
\hline $\mathrm{C7}_{\mathrm{a}}$ & - & 0 & - & 0 & - & - & - & - & 0 \\
\hline $\mathrm{C} 7_{\mathrm{b}}$ & - & 0 & 0 & - & - & - & 0 & - & - \\
\hline $\mathrm{C} 8_{\mathrm{a}}$ & - & 0 & 1 & - & - & - & - & - & - \\
\hline $\mathrm{C} 8_{\mathrm{b}}$ & - & 0 & - & 1 & - & - & - & - & - \\
\hline $\mathrm{C} 9_{\mathrm{a}}$ & - & 1 & - & 0 & - & - & - & - & 1 \\
\hline $\mathrm{C} 9_{\mathrm{b}}$ & - & 1 & 0 & - & - & - & 1 & - & - \\
\hline $\mathrm{C} 10_{\mathrm{a}}$ & 1 & - & - & 1 & - & 1 & - & - & - \\
\hline $\mathrm{C} 10_{\mathrm{b}}$ & 1 & - & 1 & - & - & - & - & 1 & - \\
\hline $\mathrm{C} 11_{\mathrm{a}}$ & 0 & - & 1 & - & - & - & - & 1 & - \\
\hline $\mathrm{C} 11_{\mathrm{b}}$ & 0 & - & - & 1 & - & 1 & - & - & - \\
\hline $\mathrm{C} 12$ & 0 & - & - & - & - & 0 & - & 0 & - \\
\hline C13 & - & 0 & - & - & - & 0 & - & 0 & - \\
\hline $\mathrm{C} 14_{\mathrm{a}}$ & - & - & - & - & - & - & - & 0 & 1 \\
\hline $\mathrm{C} 14_{\mathrm{b}}$ & - & - & - & - & - & 0 & 1 & - & - \\
\hline $\mathrm{C} 15_{\mathrm{a}}$ & - & - & - & - & - & 0 & 1 & - & 0 \\
\hline $\mathrm{C} 15_{\mathrm{b}}$ & - & - & - & - & - & - & 0 & 0 & 1 \\
\hline $\mathrm{C} 16_{\mathrm{a}}$ & - & - & 0 & 1 & - & - & - & 0 & - \\
\hline $\mathrm{C} 16_{\mathrm{b}}$ & - & - & 1 & 0 & - & 0 & - & - & - \\
\hline $\mathrm{C} 17_{\mathrm{a}}$ & - & - & 0 & 0 & - & 1 & - & 0 & - \\
\hline $\mathrm{C} 17_{\mathrm{b}}$ & - & - & 0 & 0 & - & 0 & - & 1 & - \\
\hline $\mathrm{C} 18_{\mathrm{a}}$ & - & 1 & 1 & 1 & - & 0 & - & 0 & - \\
\hline $\mathrm{C} 18_{\mathrm{b}}$ & 1 & - & 1 & 1 & - & 0 & - & 0 & - \\
\hline $\mathrm{C} 19_{\mathrm{a}}$ & 1 & 1 & 1 & 1 & - & - & - & 0 & - \\
\hline $\mathrm{C} 19_{\mathrm{b}}$ & 1 & 1 & 1 & 1 & - & 0 & - & - & - \\
\hline $\mathrm{C} 2 \mathrm{O}_{\mathrm{a}}$ & - & 0 & - & 1 & - & - & 0 & - & - \\
\hline $\mathrm{C} 2 \mathrm{O}_{\mathrm{b}}$ & - & 0 & 1 & - & - & - & - & - & 0 \\
\hline $\mathrm{C} 21_{\mathrm{a}}$ & 1 & 0 & 0 & - & - & - & 0 & - & - \\
\hline $\mathrm{C} 21_{\mathrm{b}}$ & 1 & 0 & - & 0 & - & - & - & - & 0 \\
\hline $\mathrm{C} 22_{\mathrm{a}}$ & 1 & - & 0 & - & - & 1 & - & 0 & \\
\hline $\mathrm{C} 22_{\mathrm{b}}$ & 1 & - & - & 0 & - & 0 & - & 1 & - \\
\hline $\mathrm{C} 23_{\mathrm{a}}$ & 1 & - & - & - & - & - & - & - & - \\
\hline $\mathrm{C} 23_{\mathrm{b}}$ & - & - & 1 & - & - & - & - & - & - \\
\hline $\mathrm{C} 23_{\mathrm{c}}$ & - & - & - & - & - & - & - & 1 & - \\
\hline $\mathrm{C} 23_{\mathrm{d}}$ & - & - & - & 1 & - & - & - & - & - \\
\hline $\mathrm{C} 23_{\mathrm{e}}$ & - & - & - & - & - & 1 & - & - & - \\
\hline $\mathrm{C} 24_{\mathrm{a}}$ & - & 1 & - & 1 & - & - & - & - & - \\
\hline $\mathrm{C} 24_{\mathrm{b}}$ & - & 1 & - & - & - & - & - & - & 1 \\
\hline $\mathrm{C} 24_{\mathrm{c}}$ & - & - & - & 1 & - & - & - & - & 1 \\
\hline $\mathrm{C} 24_{\mathrm{d}}$ & - & 1 & 1 & - & - & - & - & - & - \\
\hline $\mathrm{C} 24_{\mathrm{e}}$ & - & 1 & - & - & - & - & 1 & - & - \\
\hline $\mathrm{C} 24_{\mathrm{f}}$ & - & - & 1 & - & - & - & 1 & - & - \\
\hline $\mathrm{C} 25_{\mathrm{a}}$ & - & 0 & - & - & - & - & 0 & - & - \\
\hline $\mathrm{C} 25_{\mathrm{b}}$ & - & 0 & - & - & - & - & - & - & 0 \\
\hline
\end{tabular}

C8. If both interiors are disjoint, then A's boundary cannot intersect with B's interior (EH6).

C9. If A's interior intersects with $B$ 's interior and exterior, then it must intersect with B's boundary too and vice versa ( $E H 7)$.

6. At least one of the objects has a disconnected boundary: R(L,L), R(S,L), R(S,L), R(B,L), R(L,S), $\mathbf{R}(\mathbf{L}, \mathbf{S}), \mathbf{R}(\mathbf{L}, \mathbf{B})$.

C10. Line object A's boundary always intersects with at most two parts of $B$ and vice versa (EH14).

7. Objects with connected boundaries and at least one of the objects has a zero co-dimension: $R(S, S)$ in $I^{2} ; \mathbf{R}(S, B)$ and $R(B, S), R(B, B)$ in $\mathbb{I R}^{3}$.

C11. If A's boundary intersects with $B$ 's interior and exterior, then it must intersect with $B$ 's boundary too (new).

Since the co-dimension of $\mathrm{B}$ is 0 , the connected boundary of A can intersect with B's exterior and interior if and only if it intersects with B's boundary.

8. Objects with equal dimensions and zero codimensions: $R(L, L)$ in $I R ; R(S, S)$ in $\mathbb{R}^{2}$ and $R(B, B)$ in $\mathbf{I R}^{3}$.

C12. If both boundaries do not coincide, then at least one boundary must intersect with the opposite exterior (EH8). C13. If both interiors do not coincide, then at least one boundary must intersect with the opposite exterior (EH9). C14. If $A$ 's interior intersect with $B$ 's exterior, then $A$ 's boundary must also intersect with B's exterior (EH11).

9. Objects with equal dimensions and non-zero codimensions: $\mathbf{R}(L, L)$ in $\mathbf{I R}^{\mathbf{2}}$ and $\mathbf{R}(S, S)$ in $\mathbf{I R}^{3}$.

C15. If A's interior is a subset of B's interior, then A's exterior intersects with both $B$ 's boundary and $B$ 's interior and vice versa $\left(\mathrm{EH} 13_{b}\right)$.

The condition is true for every two objects of the same dimension, however when the co-dimension is zero the stricter condition $\mathrm{C} 14$ is applied. The non-zero codimension allows the intersection of the interior and the opposite exterior without crossing the boundary, therefore C14 cannot be used for the relationships $R(L, L)$ in $\mathbf{I R}^{2}$ and $\mathrm{R}(\mathrm{S}, \mathrm{S})$ in $\mathbf{I R}^{3}$.

C16. If A's interior intersects with B's boundary but A's boundary do not intersect with $B$ 's interior, then $A$ 's boundary must intersect with $B$ 's exterior and vice versa (new).

If A's interior intersects with B's boundary without crossing A's boundary, then B's interior is a subset of either A's interior or A's exterior (due to the greater than zero co-dimension). In both cases, the exterior of $\mathrm{B}$ intersects with A's boundary. The condition is true for relationships between objects of the same dimension and zero co-dimensions. In this case, B's interior is only a subset of A's interior, which can be achieved by applying C12.

10. Objects with equal dimensions, connected boundaries and non-zero co-dimensions: $R(S, S)$ in $\mathbb{I R}^{3}$. 
C17. If A's interior does not intersect with B's boundary and A's boundary does not intersect with $B$ 's interior, then both boundaries either intersect or not with both exteriors (new).

C18. If A's interior and boundary intersects respectively with $B$ 's boundary and interior, then at least one boundary intersects with the exterior of the other object (new).

C19. If A's closure intersects with B's closure, then it must intersect with B's exterior too, and vice versa (new).

11. Objects with different dimensions, non-zero codimensions and one of them with a disconnected boundary: $R(S, L)$ and $R(L, S)$ in $\mathbb{R}^{3}$.

C20. If A's interior intersects with B's boundary but not $B$ 's interior, then $B$ 's interior must intersect with $A$ 's exterior (new).

As can be realised, the condition is true for all the relationships between objects with different dimensions too; however, when the co-dimension is zero, the more restrictive condition $\mathrm{C} 8$ is applied.

$C 21$. If the boundary of $B$ intersects with the boundary of $A$ but the interior of $B$ does not intersect with both the interior and boundary of $B$, then the interior must intersect with the exterior of $A$ (new)

The condition is also true for all the relationships between objects with different dimensions; however, when the co-dimension is zero, the more restrictive condition $\mathrm{C} 7$ is applied.

12. Objects with equal dimensions, non-zero codimension and disconnected boundaries: $R(L, L)$ in $\mathbb{R}^{2}$ and $\mathbb{R}^{3}$.

C22. If A's boundary is a subset of B's boundary, then the two boundaries coincide and vice versa (EH15 a2, EH15 ${ }_{b 2}$ ).

13. At least one of the objects has empty boundary: $\mathbf{R}(\mathbf{P}, \mathbf{P}), \mathbf{R}(\mathbf{P}, \mathrm{L}), \mathbf{R}(\mathbf{P}, \mathbf{S}), \mathbf{R}(\mathbf{P}, \mathbf{B}), \mathbf{R}(\mathbf{L}, \mathbf{P}), \mathbf{R}(\mathbf{S}, \mathbf{P}), \mathbf{R}(\mathbf{B}, \mathbf{P})$. $C 23$. If A's boundary is the empty set, all the intersections between A's boundary and B's topological primitives will be the empty set and vice versa (new).

$C 24$. A's interior intersects only with one part of $B$ and vice-versa (EH2O, EH23 $\left.3_{c d}\right)$.

$C 25$. If A's interior does not intersect with $B$ 's interior, then A's exterior must intersect with $B$ 's interior and vice versa.

The set of 25 negative conditions presented here is the minimal set reported currently in the literature.

\section{Possible relationships}

The negative conditions defined above are applied to identify topological binary relationships between simple spatial objects regardless of the space in which they are embedded. A program in $\mathrm{J}$ (http://www.jsoftware.com/) computes the resulting possible relationships.
Line and line relationships in IR: Lines are spatial objects with disconnected boundaries and connected interiors. Embedded in $\mathbf{I R}$ their co-dimensions are zero. Therefore the following 19 conditions (counting all the parts of the conditions) have to be applied: $\mathrm{C} 1, \mathrm{C} 2_{\mathrm{a}}, \mathrm{C} 2_{\mathrm{b}}$, $\mathrm{C} 3_{\mathrm{a}}, \mathrm{C} 3_{\mathrm{b}}, \mathrm{C} 4_{\mathrm{a}}, \mathrm{C} 4_{\mathrm{b}}, \mathrm{C} 5_{\mathrm{a}}, \mathrm{C} 5_{\mathrm{b}} \mathrm{C} 8_{\mathrm{a}}, \mathrm{C} 8_{\mathrm{b}}, \mathrm{C} 9_{\mathrm{a}}, \mathrm{C} 9_{\mathrm{b}}, \mathrm{C} 10_{\mathrm{a}}$, $\mathrm{C} 10_{\mathrm{b}}, \mathrm{C} 12, \mathrm{C} 13, \mathrm{C} 14_{\mathrm{a}}$ and $\mathrm{C} 14_{\mathrm{b}}$. Since the two objects have equal dimension both parts of all the conditions have to be used. The number of identified possible relationships is eight and they are given the names: disjoint, contains, inside, equal, meet, covers, coveredBy, overlap. Drawings with the interacting objects can be found in [5].

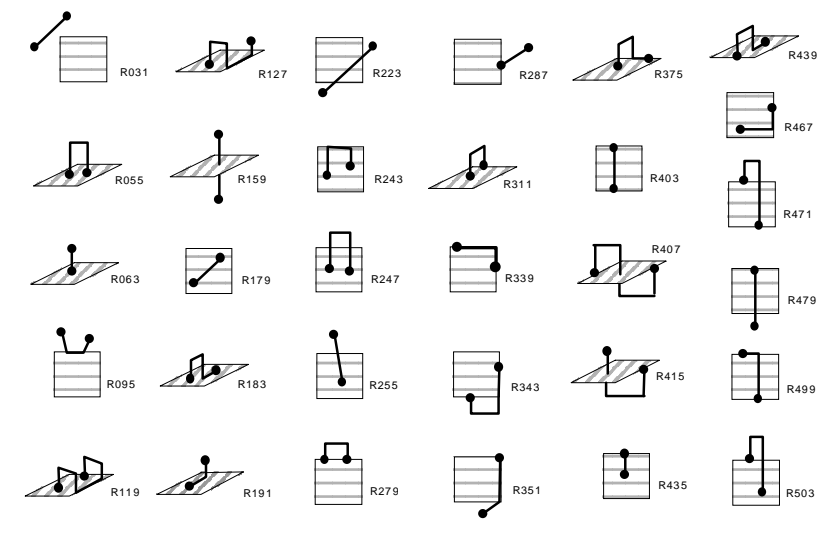

Figure 1: Surface and line in $\mathbb{R}^{3}: 31$ relationships (19 in $R^{2}$, face drawn as reactangle)

Line and line relationships in $\mathbb{R}^{2}$ and $\mathbb{R}^{3}$ : The negative conditions applicable for $R(L, L)$ in $\mathbf{I R}^{\mathbf{2}}$ and $\mathbf{I R}^{3}$ are 17: $\mathrm{C} 1, \mathrm{C} 2_{\mathrm{a}}, \mathrm{C} 2_{\mathrm{b}}, \mathrm{C} 3_{\mathrm{a}}, \mathrm{C} 3_{\mathrm{b}}, \mathrm{C} 4_{\mathrm{a}}, \mathrm{C} 4_{\mathrm{b}}, \mathrm{C} 5_{\mathrm{a}}, \mathrm{C} 5_{\mathrm{b}}, \mathrm{C} 10_{\mathrm{a}}$, $\mathrm{C} 10_{\mathrm{b}}, \mathrm{C} 15_{\mathrm{a}}, \mathrm{C} 15_{\mathrm{b}} \mathrm{C} 16_{\mathrm{a}}, \mathrm{C} 16_{\mathrm{b}}, \mathrm{C} 22_{\mathrm{a}}$ and $\mathrm{C} 22_{\mathrm{b}}$. Lines embedded in $\mathbf{I R}^{2}$ or $\mathbf{I R}^{3}$ have disconnected boundaries and connected interiors but the co-dimensions are non-zero. Therefore, the negative conditions that have to be used are the conditions for all objects, for objects of the same dimension, for objects with disconnected boundaries, for objects of the same dimension and non-zero codimension, and conditions for line and line relationships in $\mathbf{I R}^{\mathbf{2}}$ and $\mathbf{I R}^{\mathbf{3}}$. The number of all the relationships is 33 . Drawing of all the relationships are given in [6] 


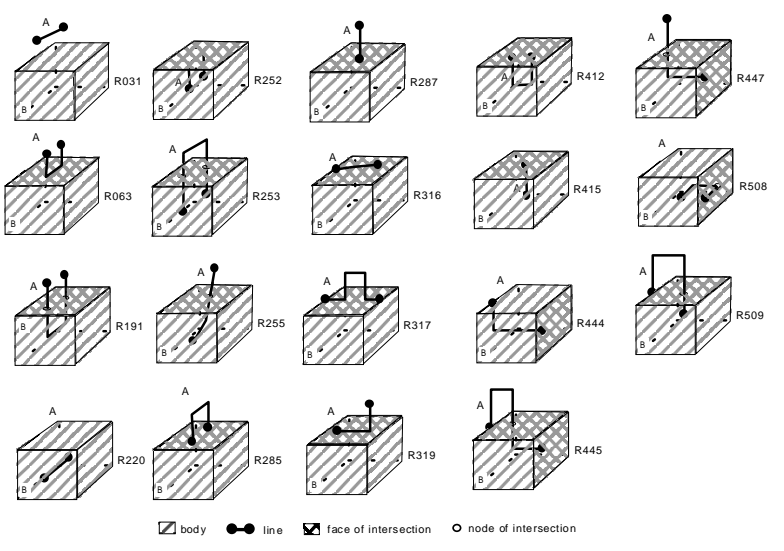

Figure 2: Body and line in $\mathbb{R}^{3}: 19$ relationships

Surface and line in $\mathbb{R}^{2}$ : The configuration surfaces and line falls in the groups of objects with different dimensions, at least one non-zero co-dimension and one disconnected boundary, i.e. the negative conditions for $\mathrm{R}(\mathrm{S}, \mathrm{L})$ are 9: $\mathrm{C} 1, \mathrm{C} 2_{\mathrm{b}}, \mathrm{C} 3_{\mathrm{b}}, \mathrm{C} 6_{\mathrm{a}}, \mathrm{C} 6_{\mathrm{b}}, \mathrm{C} 7_{\mathrm{b}}, \mathrm{C} 8_{\mathrm{b}}, \mathrm{C} 9_{\mathrm{b}}$ and $\mathrm{C} 10_{\mathrm{a}}$. The conditions leave 19 possible relationships. The examples of geometric representations are shown in

Figure 1 (the cases when the surface is represented as a rectangle are valid for 2D space).

Surface and line in $\mathbb{R}^{3}$ : Surface and line embedded in $\mathbf{I}$ ${ }^{3}$ have the same properties as surface and line in $\mathbb{R}^{2}$, but the co-dimensions are non-zero. The non-zero codimension permits 12 more configurations than in $\mathbb{R}^{3}$, i.e. the total number of all the possible relationships is 31 (see Figure 1). The conditions used for the relationship $\mathrm{R}(\mathrm{S}, \mathrm{L})$ are 8: $\mathrm{C} 1, \mathrm{C} 2_{\mathrm{b}}, \mathrm{C} 3_{\mathrm{b}}, \mathrm{C} 6_{\mathrm{a}}, \mathrm{C} 6_{\mathrm{b}}, \mathrm{C} 10_{\mathrm{a}} \mathrm{C} 20_{\mathrm{a}}$ and $\mathrm{C} 21_{\mathrm{a}}$.

Body and line in $\mathbb{R}^{3}$ : Configurations between body and line can exist only in $\mathbb{R}^{3}$, i.e. one of the codimensions is always zero. The two objects have different dimensions and one of them has disconnected boundaries. These properties require 9 negative conditions for $\mathrm{R}(\mathrm{B}, \mathrm{L})$ : $\mathrm{C} 1, \mathrm{C} 2_{\mathrm{b}}, \mathrm{C} 3_{\mathrm{b}}, \mathrm{C}_{\mathrm{a}}, \mathrm{C6}_{\mathrm{b}}, \mathrm{C} 7_{\mathrm{b}}, \mathrm{C} 8_{\mathrm{b}}, \mathrm{C} 9_{\mathrm{b}}$ and $\mathrm{C} 10_{\mathrm{a}}$; and 9 conditions for the vice-versa relationship $\mathrm{R}(\mathrm{L}, \mathrm{B}): \mathrm{C} 1, \mathrm{C} 2_{\mathrm{a}}$, $\mathrm{C}_{\mathrm{a}}, \mathrm{C6}_{\mathrm{c}}, \mathrm{C6}_{\mathrm{d}}, \mathrm{C} 7_{\mathrm{a}}, \mathrm{C} 8_{\mathrm{a}}, \mathrm{C} 9_{\mathrm{a}}$ and $\mathrm{C} 10_{\mathrm{b}}$. The comparison with the configuration surface and line in $\mathbb{R}^{2}$ shows that the negative conditions are identical and, consequently, the number of possible relationships is 19. Examples of possible geometric configurations are shown in Figure 2.

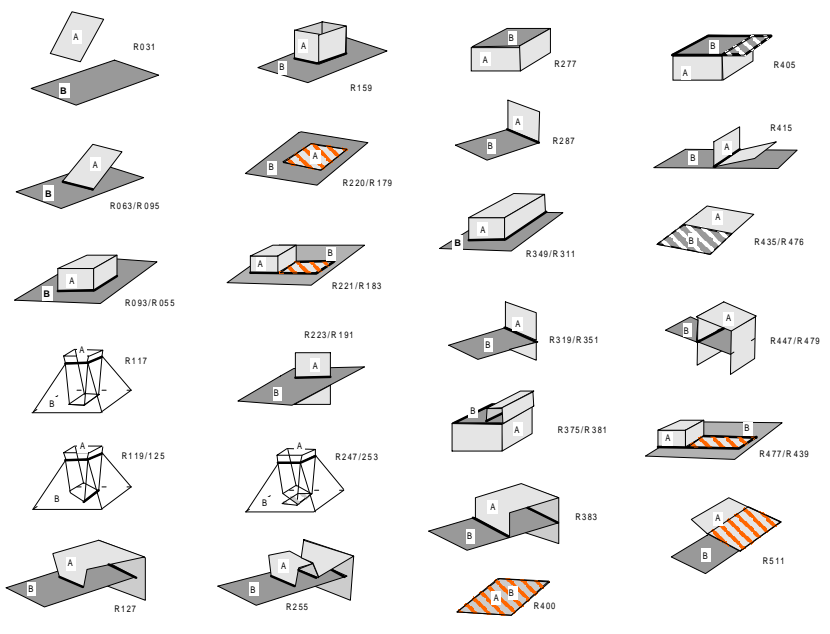
Figure 3: Surface and surface in $\mathbb{R}^{3}: 38$
relationships

Surface and surface in $\mathbb{R}^{2}$ : The configuration surface and surface in $\mathbf{R}^{2}$ has the following properties: connected boundaries, equal dimensions and zero co-dimensions. This implies that 19 negative condition has to be selected: $\mathrm{C} 1, \mathrm{C} 2_{\mathrm{a}}, \mathrm{C} 2_{\mathrm{b}}, \mathrm{C} 3 \mathrm{a}, \mathrm{C} 3_{\mathrm{b}}, \mathrm{C} 4_{\mathrm{a}}, \mathrm{C} 4_{\mathrm{b}}, \mathrm{C} 5_{\mathrm{a}}, \mathrm{C} 5_{\mathrm{b}}, \mathrm{C} 8_{\mathrm{a}}, \mathrm{C} 8_{\mathrm{b}}, \mathrm{C} 9_{\mathrm{a}}$, $\mathrm{C} 9_{\mathrm{b}}, \mathrm{C} 11_{\mathrm{a}}, \mathrm{C} 11_{\mathrm{b}}, \mathrm{C} 12, \mathrm{C} 13, \mathrm{C} 14_{\mathrm{a}}$ and $\mathrm{C} 14_{\mathrm{b}}$. The conditions are similar to the ones applied to the relationship between line and line in $\mathbf{I R}$. The only difference is $\mathrm{C} 10$, which is replaced with $\mathrm{C} 11$. Therefore the number of relationships is the same, i.e. 8 , but one relationship, i.e. R511 is new. Drawings of the possible configurations are given in [5]. Visually, the relationship R511 is the same as R255, i.e. both objects overlap each other. However, the intersections between the boundaries of topological primitives for both relationships are different.

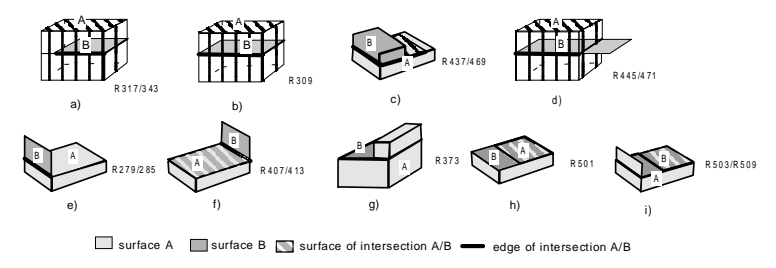

Figure 4: Examples of closed surfaces

Surface and surface in $\mathbb{R}^{3}$ : The possible relationships between surface and surface are determined by the following properties: equal dimensions, connected boundaries and non-zero co-dimensions. The conditions to be applied are 18 , i.e. $\mathrm{C} 1, \mathrm{C} 2_{\mathrm{a}}, \mathrm{C} 2_{\mathrm{b}}, \mathrm{C} 3 \mathrm{a}, \mathrm{C} 3_{\mathrm{b}}, \mathrm{C} 4_{\mathrm{a}}, \mathrm{C} 4_{\mathrm{b}}$, $\mathrm{C} 5_{\mathrm{a}}, \mathrm{C} 5_{\mathrm{b}}, \mathrm{C} 15_{\mathrm{a}}, \mathrm{C} 15_{\mathrm{b}}, 16_{\mathrm{a}}, 16_{\mathrm{b}}, \mathrm{C} 17, \mathrm{C} 18_{\mathrm{a}}, \mathrm{C} 18_{\mathrm{b}}, \mathrm{C} 19_{\mathrm{a}}$ and $\mathrm{C} 19_{\mathrm{b}}$. The number of obtained relationships is 38 (see Figure 3).

Bric [1] is the only author reporting relationships between surfaces in $\mathbf{I R}^{\mathbf{3}}$, but the obtained relationships are different. Relationships R117, R159, R277 and R405 are 
not elected as possible ones and 12 new relationships are reported, which (in our judgement) require selfintersecting surfaces. The 12 new relationships are R279, R285, R317, R343, R407, R412, R433, R445, R471, R501, R503 and R509. Relationships R279 and R285 could not be interpreted with any geometric configuration between simple surfaces; relationships R317, R343, R407, R413, R433, R445 and R471 can be realised only by a closed surface (see Figure 4).

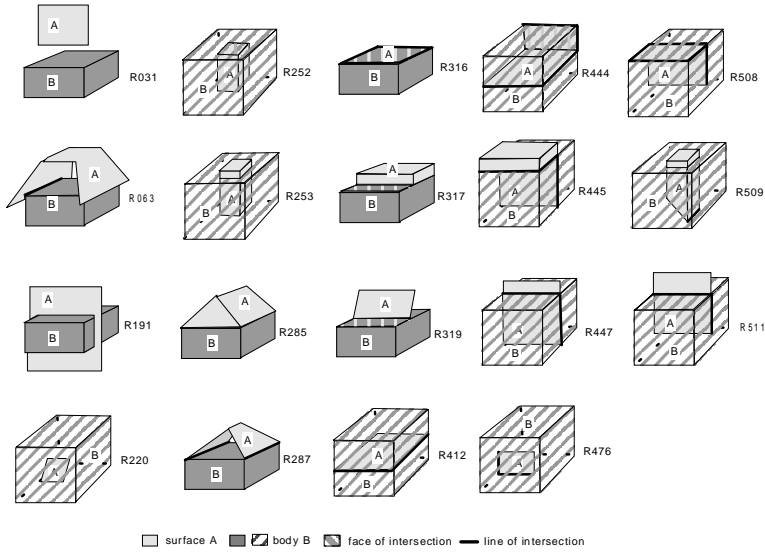

Figure 5: Body and surface in $R^{3}: 19$ relationships

Body and surface in $\mathbf{I R}^{3}$ : The configuration body and surface in $\mathbf{I R}^{3}$ has similar characteristics to surface and line in $\mathbf{I R}^{\mathbf{2}}$, i.e. one of the objects has a co-dimension zero. However, the line has disconnected boundaries. Therefore, the condition $\mathrm{C} 10$, which refers to disconnected boundaries, must be replaced with $\mathrm{C} 11$. Thus the set of possible relationships $\mathrm{R}(\mathrm{B}, \mathrm{S})$ can be obtained by 9 conditions: $\mathrm{C} 1, \mathrm{C} 2_{\mathrm{b}}, \mathrm{C} 3_{\mathrm{b}}, \mathrm{C} 6_{\mathrm{a}}, \mathrm{C} 6_{\mathrm{b}}, \mathrm{C} 7_{\mathrm{b}}$, $\mathrm{C} 8_{\mathrm{b}}, \mathrm{C} 9_{\mathrm{b}}$ and $\mathrm{C} 11_{\mathrm{b}}$. The conditions $\mathrm{C} 1, \mathrm{C} 2_{\mathrm{a}}, \mathrm{C} 3_{\mathrm{a}}, \mathrm{C} 6_{\mathrm{c}}, \mathrm{C} 6_{\mathrm{d}}$, $\mathrm{C} 7_{\mathrm{a}}, \mathrm{C} 8_{\mathrm{a}}, \mathrm{C} 9_{\mathrm{a}}$ and $\mathrm{C} 11_{\mathrm{a}}$ determine all the converse relationships, i.e. $\mathrm{R}(\mathrm{S}, \mathrm{B})$. The number of the relationships is 19 (see Figure 5). The comparison between surface and line in $\mathbf{I R}^{2}$ (see

Figure 1), and body and surface in $\mathbf{I R}^{3}$ (see Figure 5) shows difference only in one relationship, i.e. R255, which is replaced by $\mathrm{R} 511$.

Body and body in $\mathbb{R}^{3}$ : The properties of this configuration are equal to the properties surface and surface in 2D space, i.e. equal dimensions, connected boundaries, and zero co-dimensions. Therefore the same 19 negative conditions must be applied, i.e. $\mathrm{C} 1, \mathrm{C} 2_{\mathrm{a}}, \mathrm{C} 2_{\mathrm{b}}$, $\mathrm{C} 3 \mathrm{a}, \mathrm{C} 3_{\mathrm{b}}, \mathrm{C} 4_{\mathrm{a}}, \mathrm{C} 4_{\mathrm{b}}, \mathrm{C} 5_{\mathrm{a}}, \mathrm{C} 5_{\mathrm{b}}, \mathrm{C} 8_{\mathrm{a}}, \mathrm{C} 8_{\mathrm{b}}, \mathrm{C} 9_{\mathrm{a}}, \mathrm{C} 9_{\mathrm{b}}, \mathrm{C} 11_{\mathrm{a}}$, $\mathrm{C} 11_{\mathrm{b}}, \mathrm{C} 12, \mathrm{C} 13, \mathrm{C} 14_{\mathrm{a}}$ and $\mathrm{C} 14_{\mathrm{b}}$. The number of possible relationships is again 8 . Examples of possible geometric configurations can be found in [5].

Point and point: Since the points are objects with empty boundaries and equal dimensions, the conditions that have to be applied are 10: $\mathrm{C} 1, \mathrm{C} 23_{\mathrm{a}}, \mathrm{C} 23_{\mathrm{b}}, \mathrm{C} 23_{\mathrm{c}}$,
$\mathrm{C} 23_{\mathrm{d}}, \mathrm{C} 23_{\mathrm{e}}, \mathrm{C} 24_{\mathrm{b}}, \mathrm{C} 24_{\mathrm{e}}, \mathrm{C} 25_{\mathrm{a}}$ and $\mathrm{C} 25_{\mathrm{b}}$. These conditions eliminate 510 relationships and leave only two, i.e. equal and disjoint

Point and any other object $X: \mathbf{R}(\mathbf{P}, \mathbf{X}), \mathbf{R}(\mathbf{X}, \mathbf{P})$. The relationships between a point and any other object are only three, i.e. a point can be disjoint, lay on the boundary or the interior of the object. These configurations can be obtained by applying 11 conditions for $\mathrm{R}(\mathrm{P}, \mathrm{X})$ : $\mathrm{C} 1, \mathrm{C} 6_{\mathrm{c}}$, $\mathrm{C} 6_{\mathrm{d}}, \mathrm{C} 7_{\mathrm{a}}, \mathrm{C} 23_{\mathrm{a}}, \mathrm{C} 23_{\mathrm{b}}, \mathrm{C} 23_{\mathrm{c}}, \mathrm{C} 24_{\mathrm{a}}, \mathrm{C} 24_{\mathrm{b}}, \mathrm{C} 24_{\mathrm{c}}$ and $\mathrm{C} 25_{\mathrm{a}}$; and 11 conditions for $\mathrm{R}(\mathrm{X}, \mathrm{P})$ : $\mathrm{C} 1, \mathrm{C} 6_{\mathrm{a}}, \mathrm{C} 6_{\mathrm{b}}, \mathrm{C} 7_{\mathrm{b}}, \mathrm{C} 23_{\mathrm{a}}$, $\mathrm{C} 23_{\mathrm{d}}, \mathrm{C} 23_{\mathrm{e}}, \mathrm{C} 24_{\mathrm{d}}, \mathrm{C} 24_{\mathrm{e}}, \mathrm{C} 24_{\mathrm{f}}$ and $\mathrm{C} 25_{\mathrm{b}}$.

The comparison between conditions used by different authors (complete lists are given in [1],[6]), shows a significant reduction in the number needed for each configuration of objects. For example, Bric 1993 has obtained the relationships between surface and line applying 14 conditions, between body and line applying 15 conditions, and body and surface applying 16 conditions. Egenhofer and Herring 1992 have reported 20 conditions for line and line, 19 conditions (one less than above) for line and surface but have obtained one relationship more, i.e. R511, which is impossible for simple lines and surfaces.

\section{Conclusions}

This paper presents a unified set of conditions for deriving the possible relationships between multidimensional simple spatial objects in 1,2 and 3D space. The conditions are systemised on the basis of dimension, co-dimension and connectivity of boundaries. Thus most of the conditions (15 of 23, see [6]) derived for $2 \mathrm{D}$ space are propagated in $3 \mathrm{D}$ space and the overal number of conditions is reduced. All the relationships derived are verified with drawings. This proves that all the conditions are "sufficiently" restrictive, i.e. there is not a configuration left that cannot be represented by an appropriate drawing. Indeed, the question "Are the conditions too restrictive?" is also valid. Too restrictive conditions will eliminate relationships that are possible and, practically, there is not a way to detect this effect. As was shown above (e.g. R159 for surface and surface in 3D), relationships between complex objects might be influenced. Additional analysis of the intersections between exteriors contribute to the negative answer (see[13]).

Applying these negative conditions, the total number of relationships that can be identified by the 9-intersection and hence has to be considered for implementation, is reduced to 69 . Note that the number of relationships concerns simple spatial object, e.g. surfaces with holes or bodies with tunnels might have different relationships.

Analysing the derived topological relationships, several conclusions can be drawn that can be of favour at the implementation level: 
The topological relationships are related to the types of objects, i.e. some of the relationships never occur between particular types. For example, R509 is possible only between body and line and body and surface. This implies that certain relationships (respectively the intersections between the topological primitives) may not be checked, if the dimension of the objects is known in advance.

The relationships are related to the geometric partitioning performed for a particular application. This is to say that some relationships may not be needed because the geometric partitioning of the object is not appropriate. For example R455 performed for body and surface may never be needed for urban applications.

The study clearly shows inefficiency and insufficiency of the verbal identification of relationships. Some of the names established for relationships in 2D space are not applicable for relationships between 3D objects. The relationships between surfaces in $3 \mathrm{D}$ space are one typical example. Some of the names refer to formally different relationships, e.g. overlap stands for R511 (e.g. surface and surface in 2D) and R255 (e.g. surface and line in 3D). Most of the relationships are not associated with appropriate names and even it is difficult to specify the type of interaction. Many examples can be found among the relationships between body and surface or body and line. In this respect a unified coding of the relationships (similar to the coding used here) might be an alternative.

Having specified the conditions for multidimensional simple objects, the next step has to be toward an extension for identifying conditions for surfaces with holes and bodies with tunnels.

\section{Acknowledgements}

I express my sincere gratitude to Dr. Ben Gorte the author of the J-program used for the combinatorial computations.

\section{References}

[1] Bric, V., 1993, 3D Vector data structures and modelling of simple objects in GIS, MSc thesis, ITC, The Netherlands

[2] Clementini, E., P. di Felice and P. van Oosterom, 1993, A small set of formal topological relations suitable for end-user interaction, in: Proceedings of the 3th International Symposium on large spatial databases, Springer-Verlag, Berlin, pp. 277-295
[3] Clementini, E, J. Sharma and M. Egenhofer, 1994, Modelling topological spatial relations: strategies for query processing, Computer and graphics, 18 (6): pp. 815-822

[4] de Hoop, S., L. van de Meij and M. Molenaar, 1993, Topological relations in 3D vector maps, in: Proceedings of 4th EGIS, Genoa, Italy, pp. 448-455

[5] Egenhofer, M. J., 1995, Topological relations in 3D, Technical report, University of Maine, USA

[6] Egenhofer, M. J. and J. R Herring, 1992, Categorising topological relations between regions, lines and points in geographic databases, in: The 9-intersections: formalism and its use for natural language spatial predicates, Technical report 94-1, NCGIA, University of California

[7] Egenhofer, M. J. and J. R. Herring, 1990, A mathematical framework for the definition of topological relations, in: Proceedings of Fourth International Symposium on SDH, Zurich, Switzerland, pp. 803-813

[8] Egenhofer, M., J. Sharma, and D. Mark, 1993, A critical comparison of the 4-Intersection and 9-Intersection models for spatial relations: formal analysis. in: Autocarto 11, Minneapolis, MN, pp. 1-11.

[9] Hazelton, N. W., L. Bennett, and J. Masel, 1992, Topological

Structures for 4-Dimensional Geographic Information Systems, in: Computers, Environment, and Urban Systems 16(3), 227237.

[10] Kufoniyi, O., 1995, Spatial coincidence modelling, automated database updating and data consistency in vector GIS, PhD thesis, ITC, The Netherlands

[11] van der Meij, L., 1992, Topologische relaties en bevragingen in een formele datastructuur voor drie-dimensionale vectorkaarten, Technical report, WAU, The Netherlands

[12] van Oosterom, P. , W. Vertegaal, M. van Hekken, 1994, Integrated modelling within 3D GIS, Proceedings of AGDM'94, Delft, the Netherlands, pp. 80-95

[13] Zlatanova, S., 2000, 3D GIS for urban development, $\mathrm{PhD}$ thesis, ITC, the Netherlands (to be published). 